\title{
The Hemibiotroph Colletotrichum graminicola Locally Induces Photosynthetically Active Green Islands but Globally Accelerates Senescence on Aging Maize Leaves
}

\author{
Michael Behr, ${ }^{1}$ Klaus Humbeck, ${ }^{2}$ Gerd Hause, ${ }^{3}$ Holger B. Deising, ${ }^{1}$ and Stefan G. R. Wirsel ${ }^{1}$ \\ ${ }^{1}$ Institut für Agrar- und Ernährungswissenschaften, Naturwissenschaftliche Fakultät III, Martin-Luther-Universität Halle- \\ Wittenberg, Betty-Heimann-Str. 3, D-06120 Halle (Saale), Germany; ${ }^{2}$ Institut für Biologie, Naturwissenschaftliche Fakultät I, \\ Martin-Luther-Universität Halle-Wittenberg, Weinbergweg 10, D-06120 Halle (Saale), Germany; ${ }^{3}$ Biozentrum der Martin- \\ Luther-Universität Halle-Wittenberg, Weinbergweg 22, D-06120 Halle (Saale), Germany
}

Submitted 19 December 2009. Accepted 16 March 2010.

Typically, pathogenesis of the hemibiotroph Colletotrichum graminicola and defense responses of its host, Zea mays, are studied on young leaves. Equivalent studies have not been performed with leaves undergoing senescence, a situation that is relevant in the field. We discovered that, in contrast to anthracnose symptoms formed on young and mature leaves, green islands reminiscent of those known from obligate biotrophs were formed on senescing leaves. Microscopy revealed that the fungus grew in both symptoms from the epidermis towards the bundle sheath. In green islands, tissues remained intact for an extended time period. Imaging PAM (pulse-amplitude-modulation) fluorescence analyses revealed that photosynthesis is transiently maintained at green islands but declined in tissue surrounding the infection. In younger leaves however, photosynthesis was reduced only at infection sites. Support for the local modification of host physiology came from quantitative reverse transcription-polymerase chain reaction analyzing gene expression at high spatial resolution. Decreased transcript levels of the senescence markers see 1 and $c c p 1$ corroborated a pathogen-induced delay of senescence. Expression of several genes encoding proteins involved in photosynthesis was strongly reduced by infection. In contrast, transcript levels of incw1, encoding a cell-wall invertase, were increased 70-fold at green islands, suggesting that $C$. graminicola induced carbon sinks in senescing tissue.

Phytopathogenic fungi exhibit several lifestyles ranging from necrotrophy to obligate biotrophy. After germination of spores on a host surface, necrotrophic species overcome defense reactions by killing host cells, for instance, through the secretion of phytotoxic compounds (Howlett 2006). This enables them, without needing to cope with effective host defenses, to feed on dead tissues and to reproduce, typically by the production of asexual or sexual spores. At the other extreme, obligate biotrophs such as rust fungi grow in living tissues, in which they penetrate host cells with a highly spe-

Corresponding author: S. G. R. Wirsel; Telephone: +49 (0)345 5522672; Fax: +49 (0)345 5527120; E-mail: stefan.wirsel@landw.uni-halle.de

* The $e$-Xtra logo stands for "electronic extra" and indicates that a supplementary figure and a supplementary table are published online. cialized structure, the haustorium (Voegele et al. 2009). This cell secretes effector molecules that may suppress host defense responses and maintains the biotrophic interaction, often for weeks, with only limited damage to the host (Ellis et al. 2007). During this phase, the fungus absorbs nutrients from living host cells through the haustorium, which are then distributed through the mycelium and used to produce masses of spores that, under favorable conditions, can lead to an epidemic.

Hemibiotrophic fungi, such as the maize pathogen Colletotrichum graminicola, have a lifestyle that combines both of these extremes. To infect maize, leaf spores develop a short germ tube and differentiate a melanized appressorium from which a penetration hypha breaches an epidermal cell (Bechinger et al. 1999; Bergstrom and Nicholson 1999). Within this first infected host cell, the fungus forms an infection vesicle from which thick, primary hyphae emerge. Both fungal cell types, which probably have a function similar to the haustorium of obligate biotrophs, are engulfed by the plasma membrane of the host. Fungal and plant cell membranes are separated by an interfacial matrix. In $C$. graminicola, this biotrophic phase is sequential, i.e., it spreads to a few surrounding cells and lasts for about two days (Mims and Vaillancourt 2002). The necrotrophic phase is initiated by subsequently formed thinner secondary hyphae that proliferate through and necrotize the tissue (Bergstrom and Nicholson 1999). The fungus produces substances in vitro that induce necrotic lesions when partially purified fractions were tested on maize leaves (Amusa 1994). Recent studies employing mutants deficient in 4'-phosphopantetheinyltransferase, a central regulator of fungal secondary metabolism, suggested that synthesis of the toxin is dependent on the activity of a polyketide synthase (PKS), a nonribosomal peptide synthetase (NRPS), or a PKSNRPS hybrid (Horbach et al. 2009). After about three days, symptoms initially appear as chlorotic spots that turn to grayish, dry necrotic lesions, a symptom referred to as anthracnose (Bergstrom and Nicholson 1999). In the field, leaves carrying anthracnoses fall to the ground and splashing rain drops spread spores, allowing initiation of a new infection cycle.

Typically, for experimental infection assays, conidia of $C$. graminicola are inoculated onto young maize plantlets. Fungal development is thus studied on young, green leaves conducting photosynthesis and actively producing carbohydrates. In the field however, spores may preferentially be inoculated onto older leaves close to the ground. In contrast to the knowledge 
established for pathogenesis on young leaves, development of $C$. graminicola on leaves that have initiated senescence is unknown, and putative host responses have not been studied in older leaves. In maize, senescence progresses from the bottom to the top of the plant. Within a leaf, senescence starts at the tip and proceeds to its base. The onset of senescence is controlled by a variety of factors, such as phytohormone levels and external stimuli like extremes of temperature, drought, and pathogens.

In this study, we assess physiological responses of maize to an infection by $C$. graminicola. The discovery of green islands on senescing leaves, reminiscent of those formed by obligate biotrophs, allows for analyzing, in a single pathosystem, of influence of the developmental stage of the host on fungal pathogenesis. For both mature and old leaves, we examine, at high spatial resolution, fungal and symptom development, the consequences of infection on photosynthetic activity, and expression of maize genes regarded as markers for senescence, photosynthesis, and source-sink status. The obtained results suggest that depending on its developmental stage host metabolism is differentially modulated by fungal infection.

\section{RESULTS}

\section{C. graminicola causes contrasting symptoms on young and old leaves of maize.}

In contrast to previous reports that used young maize plants to investigate only the infection of mature leaves with $C$. graminicola, we also analyzed infection on old leaves at different stages of senescence. To determine in detail the impact of C. graminicola on leaves of different ages, we macroscopically observed leaf and disease symptom development of 28-day-old plants after spray inoculation with conidia for nine days. Visual changes as typically observed on infected leaves 2,4 , and 5 were compared with corresponding mock-inoculated controls (Fig. 1 A). The oldest control leaf shown (no. 2) started to senesce shortly after the beginning of the experiment, which continued until the leaf showed only a brownish color at $8 \mathrm{dpi}$ (days past inoculation). Leaf 4 initiated senescence at $8 \mathrm{dpi}$ and leaf 5 showed no senescence over the time period of the experiment. Infection with $C$. graminicola seemed to accelerate senescence in leaves 2 and 4 but not in the younger leaf 5 . The effects of infection on the time course of leaf senescence in mature and senescing leaves of different stages were investigated in more detail using chlorophyll fluorometry for quantitative detection of changes in relative electron transport rate (ETR) as a sensitive parameter (Fig. 2). Due to degradation of the photosynthetic machinery, ETR decreases with the onset of senescence, and a strict correlation between the leaf number and the onset of senescence was observed (Fig. 2A through E). Inoculation with $C$. graminicola clearly accelerated senescence processes, as revealed by a quicker decrease in ETR after infection (Fig. 2A through E). In inoculated leaves 1 through 3, the final stage of senescence indicated by a total loss of electron transport capacity was already reached 3 to $4 \mathrm{dpi}$, while noninfected controls stayed photosynthetically active much longer. In contrast in leaf 5, no substantial differences in ETR between controls and infected leaves were observed within 5 dpi. Only thereafter did ETR values start to decrease more quickly in the infected leaf. At saturating light intensities, which were used for the measurements of relative ETR, differences in photosynthetic ETR between control and infected leaves were mostly significant $(P \leq 0.05)$ (Fig. $2 \mathrm{~A}$ to $\mathrm{E})$. As demonstrated for leaf 4 at 4 and 6 dpi as an example, infection resulted in a decrease of ETR at both low and high light intensities (Fig. 2F).

As shown in Figure 1A, leaves undergoing accelerated yellowing after inoculation with $C$. graminicola showed a phe- nomenon not observed when young leaves were infected. The older leaves (numbers 2, 3 and 4), depending on space and time, formed green spots, referred to as green islands. These were not observed on younger leaves (leaves 5 and 6), in which inoculation resulted in typical symptoms reported for $C$. graminicola, i.e., initial chlorotic spots that eventually developed to anthracnoses (Fig. 1C). Green islands only occurred at stages in which the affected leaves were still yellow. On leaf 4, green islands lasted from about 4 to 6 dpi and on leaf 2 from 2 to 3 dpi (Fig. 1A and B). On the other leaves, green islands appeared correspondingly, i.e., on leaf 1 , only at 2 dpi and on leaf 3 from 3 to $4 \mathrm{dpi}$, whereas leaf 5 already exhibited chloroses and later anthracnose symptoms. At a certain time during early senescence, the distribution of green islands paralleled the progression of senescence (Fig. 1C). To show that our observation was not restricted to one cultivar, we also inoculated the cultivars Golden Jubilee, Doge, Nathan, and Amadeo. In all cases, we observed the formation of green islands on lower leaves when 28-day-old plants were inoculated (not shown).

\section{Contrasting effects of infection on local photosynthesis in young and old leaves.}

The above experiments established that an infection by $C$. graminicola can result in different symptoms on maize leaves depending on the developmental stage of the host. We investigated the underlying physiological causes by assessing the effects of infection on photosynthesis for both symptoms at a high spatial resolution. Leaves from spray-inoculated whole plants were taken daily from 0 to $9 \mathrm{dpi}$ and were analyzed by Imaging PAM (pulse-amplitude-modulation) chlorophyll fluorometry, a method that allows for noninvasive evaluation of photosynthesis, particularly with regard to the detection of heterogeneities at high spatial resolution. To visualize the effects of fungal infection, we chose the sensitive photosynthesis parameters Fv/Fm (maximal photosystem II [PS II] quantum yield), yield (effective PS II quantum yield), and NPQ/4 (nonphotochemical quenching) (Fig. 3). A decrease in maximal and effective quantum yield and a concomitant increase in nonphotochemical quenching processes during degradation of the photosynthetic apparatus are sensitive markers for changes in photosynthetic performance in response to infection (Bonfig et al. 2006). On infected leaf 5, showing anthracnose symptom development, first spots with reduced quantum yield of PS II and increased nonphotochemical quenching became visible at 3 dpi (Fig. 3B). The initial small chlorotic spots with reduced photosynthetic activity (Fig. 1) expanded over time and progressed to a state in which virtually no local photosynthetic activity remained, as indicated by black areas in the image. Leaf areas surrounding these spots remained photosynthetically fully active (Fig. 3B and D). On the other hand, leaf 4, exhibiting the development of green islands, showed a different pattern, because it generally lost photosynthetic activity early after inoculation except at sites that exactly matched the green islands (Fig. 3A). Thus, green islands retained photosynthetic activity against a 'dying' background. At higher resolution, we observed, at $4 \mathrm{dpi}$, that the center of green islands exhibited a somewhat reduced activity that was surrounded by a ring of cells with higher photosynthetic activities (Fig. 3C). This reflected beginning necrosis in the central epidermal cells, which was also observed by microscopy at this stage (described below).

In addition to qualitative assessment of photosynthesis (Fig. 3 ), we performed quantitative analyses of individual symptoms (Fig. 4). For this purpose, at the same plant chlorotic spots on leaf 5 and green islands on leaf 4 and their corresponding surrounding areas were analyzed by Imaging PAM at 4 dpi at high resolution. Measuring Fv/Fm and yield at randomly dis- 
tributed areas of noninfected controls yielded similar results for leaves 4 and 5, indicating that both leaves were mature at this stage (Fig. 4A and B, left sides). Areas measured outside of chlorotic spots on infected leaf 5 yielded similar results for both parameters, demonstrating that infection had only local effects on photosynthesis. In contrast, Fv/Fm and yield were significantly $(P \leq 0.05)$ reduced on infected leaf 4 outside of green islands, reflecting the globally accelerated senescence described above (Figs. 1A and 2D). The centers of both symptoms exhibited levels of Fv/Fm and yield that were both significantly $(P \leq 0.05)$ decreased compared with the corresponding noninfected controls (Fig. 4A and B). The third parameter analyzed, NPQ/4, was significantly $(P \leq 0.05)$ higher in noninfected control leaf 4 than in leaf 5 , suggesting that the older
A Leaf No. 2

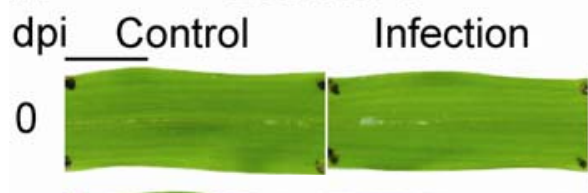

1

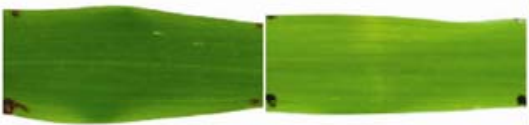

2

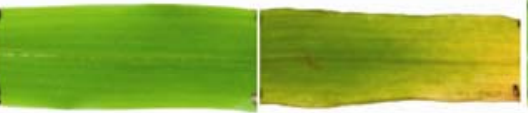

3



4

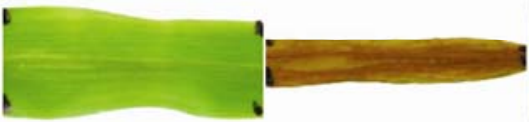

5

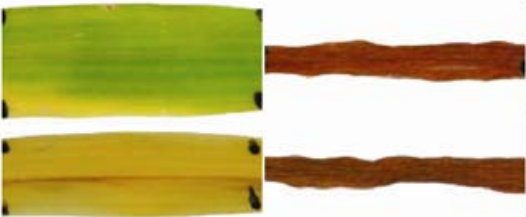

6



8

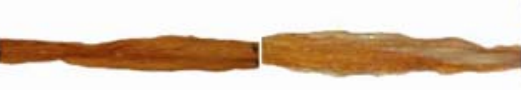

9
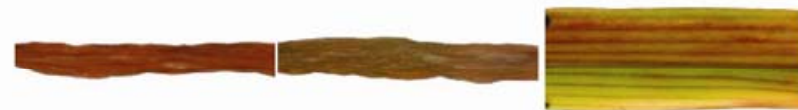

B

Green islands

\section{Chlorotic spots}
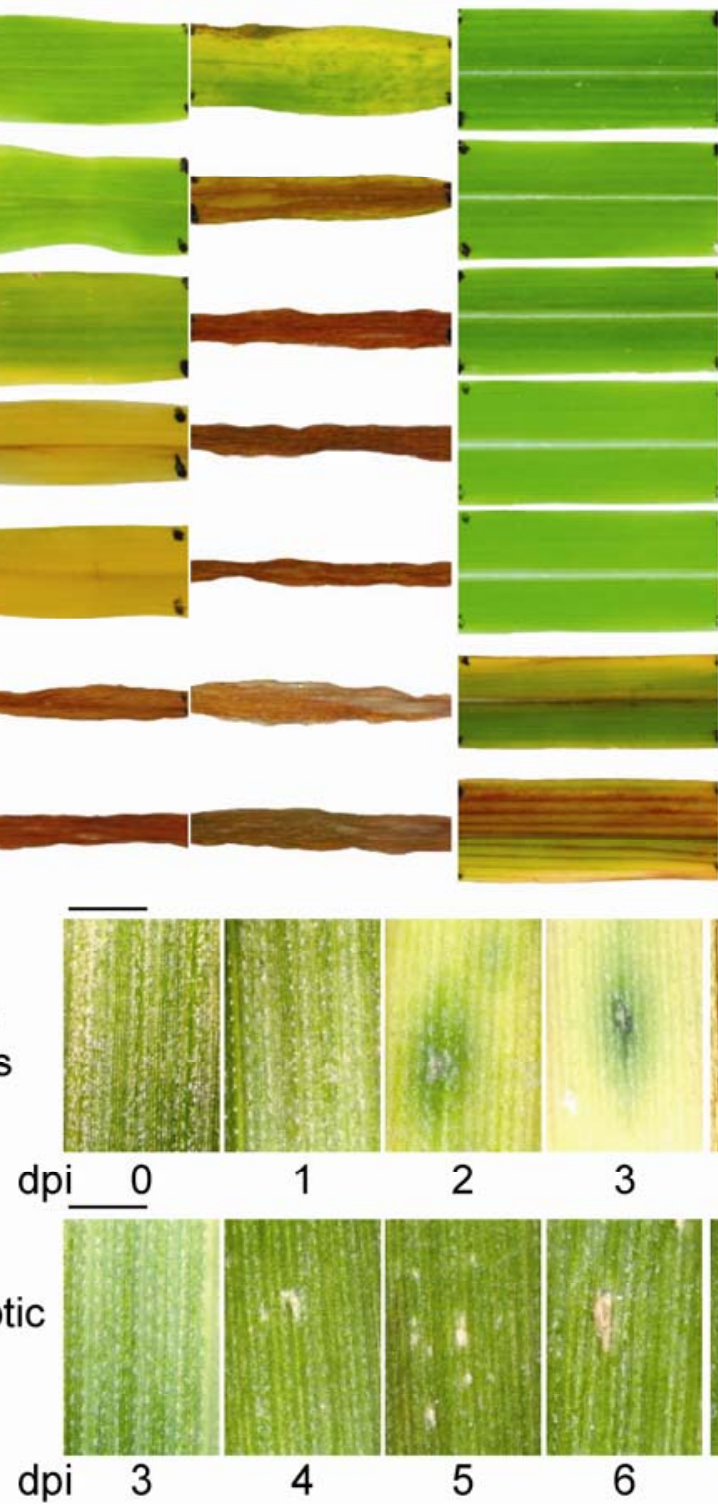

Leaf No. 4
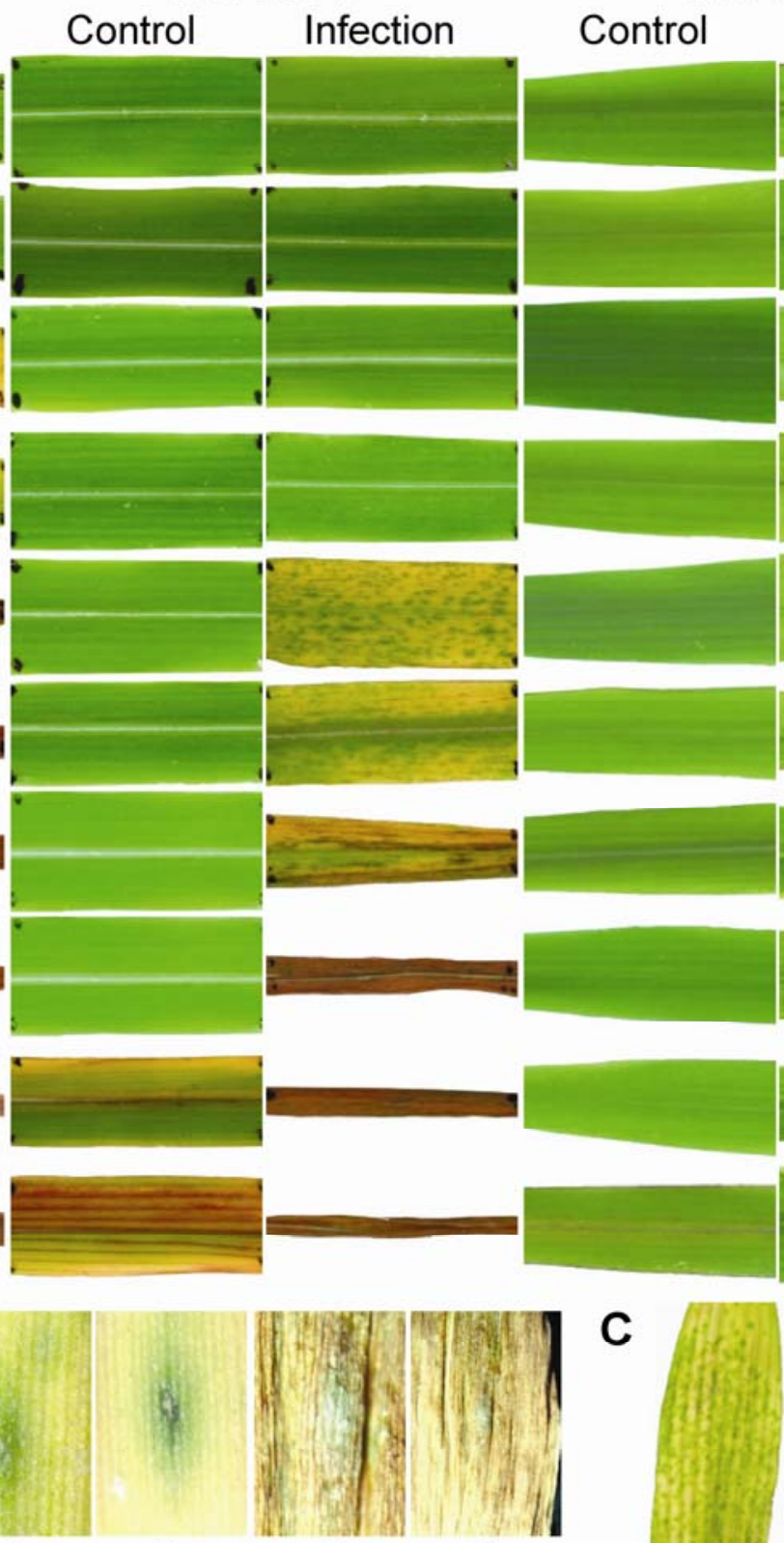

4

5

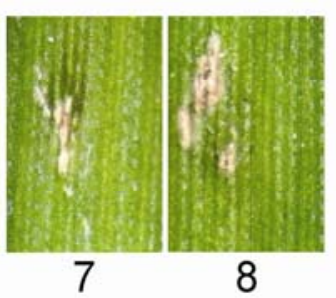

C

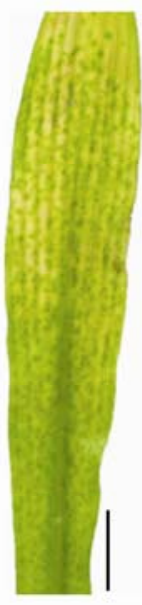

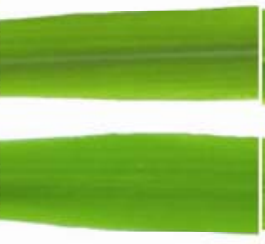


Leaf No. 5

\section{Control Infection}
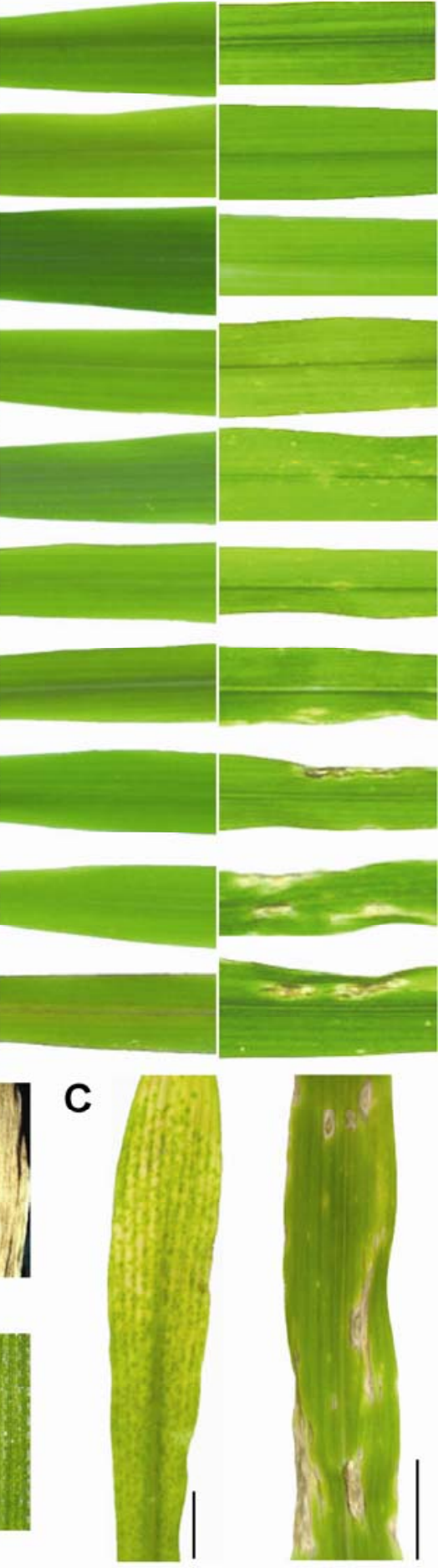

Fig. 1. Symptom development on maize leaves infected by Colletotrichum graminicola. A, Photos were taken from 0 to 9 days past inoculation (dpi) from middle segments of leaves numbered 2, 4, and 5. B, Micrographs (63×) of a single green island on leaf 2 and a chlorotic spot on leaf 5. C, Leaf 4 at 4 dpi and leaf 5 at $8 \mathrm{dpi}$, showing fully developed green islands and anthracnoses, respectively. Plants were 28 days old when inoculated. Bars represent $1 \mathrm{~cm}$ in $\mathrm{A}$ and $\mathrm{C}$ and $0.5 \mathrm{~cm}$ in $\mathrm{B}$. 
leaf dissipated more of the absorbed light energy that could not be used in photosynthesis (Fig. 4C). Despite these differences seen between the controls, infected leaves showed, at the centers of both symptoms, the same levels of NPQ/4, which corresponded to a significant $(P \leq 0.05)$ increase for chlorotic spots compared with the appropriate noninfected leaf. This indicated that, in the chlorotic spots on the younger leaf, nonphotochemical quenching mechanisms were increased due to impaired photosynthetic activities. The areas surrounding this symptom and, even more, those surrounding green islands exhibited significantly $(P \leq 0.05)$ reduced levels of NPQ/4 compared with the centers of the corresponding symptoms. Analyses of photosynthesis parameters Fv/Fm and yield recorded for transects across the symptoms (Fig. 4A and B, right sides) also showed the difference between green islands and chlorotic spots. Within the chlorotic spots on the younger leaf, these parameters decreased, whereas they were high in the area of green islands. In contrast, the stress- and senescence-induced nonphotochemical quenching was increased only in the chlorotic spots (Fig. 4C, right side).

\section{C. graminicola induces distinct host responses on young and old leaves.}

To analyze both symptoms by microscopy, we first examined the effect of inoculation density. Increasing concentrations of spores sprayed onto 28-day-old maize plants resulted in similar dosage-response curves when counting, at $4 \mathrm{dpi}$, macroscopically visible chlorotic spots on leaf 5 and green islands on leaf 4 (Fig. 5A). High spore densities lead to the saturation of the numbers (Fig. 5A) and the reduction in size of both symptoms (not shown). At a concentration of $1 \times 10^{6}$ spores per milliliter, we microscopically observed, for $70.4 \%$ of the green islands and for $69.6 \%$ of the chlorotic spots, a single appressorium within the areas covered by individual symp-
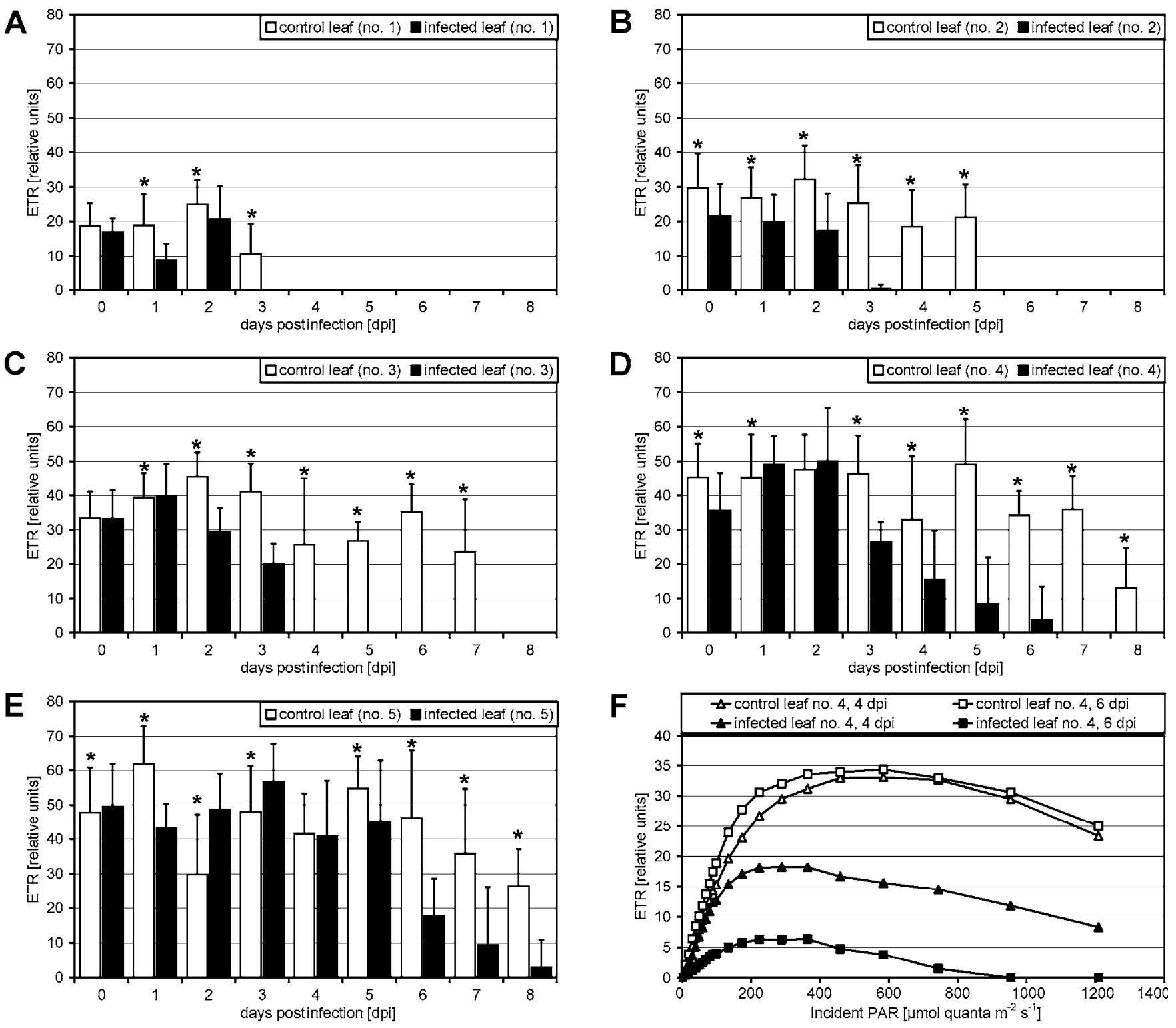

Fig. 2. Changes in relative electron transport rate (ETR) on maize leaves infected by Colletotrichum graminicola. A to E, Relative ETR recorded for leaves numbered 1 to 5 , light intensity for detection was $584 \mu \mathrm{E} \mathrm{m}^{-2} \mathrm{~s}^{-1}$. Significant differences $(P \leq 0.05)$ between controls and infections as detected by the HolmSidak test are indicated by an asterisk on top of the corresponding control column. F, Light intensity curves of control and infected leaf 4 , taken at 4 and 6 days past inoculation (dpi). Plants were 28 days old when inoculated. Error bars represent standard deviations. Significant differences $(P \leq 0.05)$ between controls and infections were detected by the Holm-Sidak test from 69 to $1,209 \mu \mathrm{mol}$ quanta $\mathrm{m}^{-2} \mathrm{~s}^{-1}$ at $4 \mathrm{dpi}$ and from 29 to $1,209 \mu \mathrm{mol}$ quanta $\mathrm{m}^{-2} \mathrm{~s}^{-1}$ at 6 dpi (not shown). 


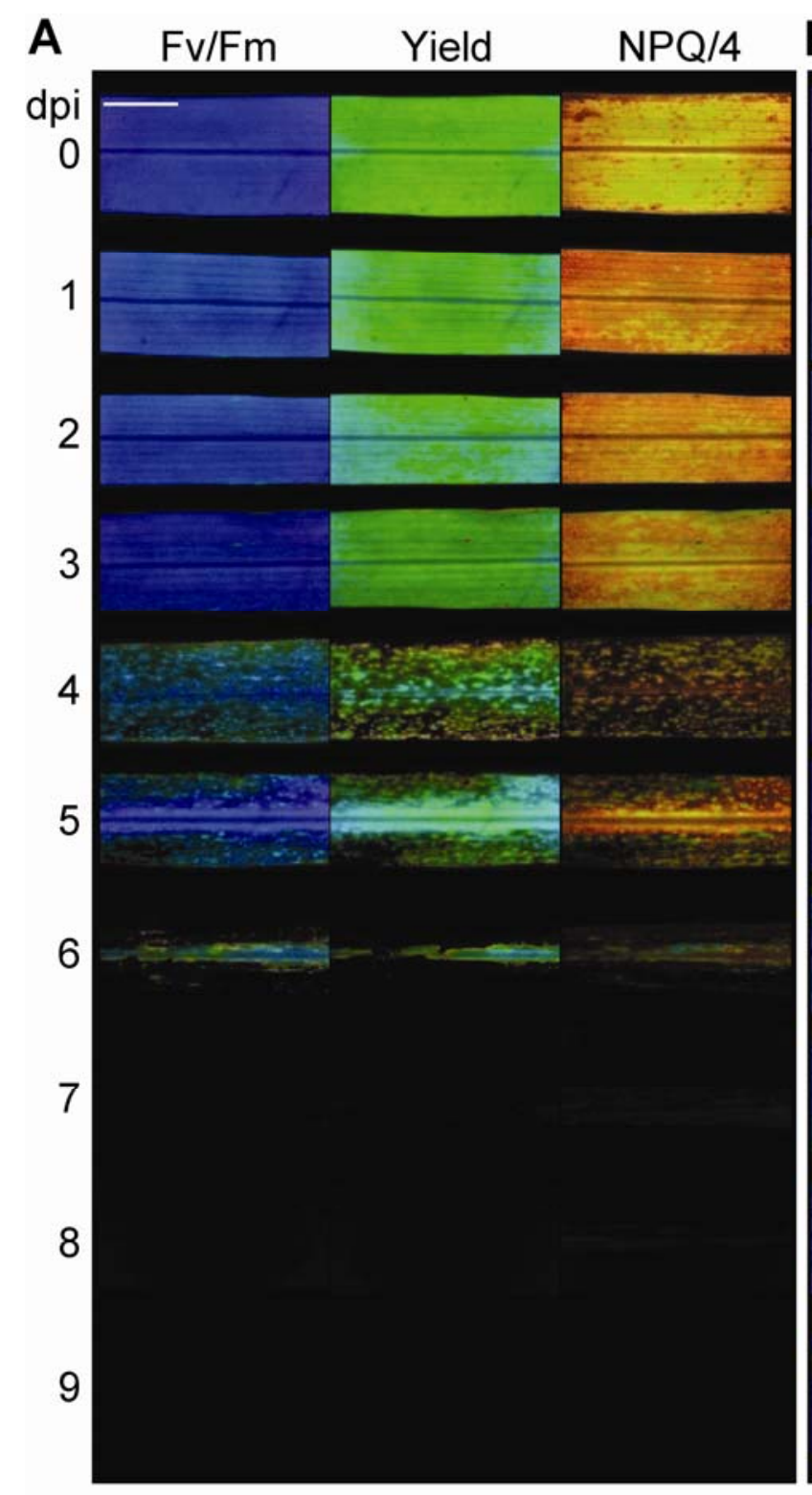

\section{B Fv/Fm $\quad$ Yield NPQ/4}


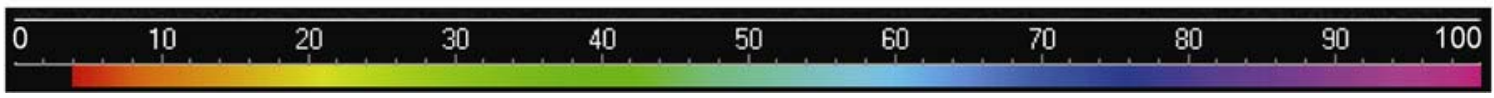

Fig. 3. Imaging PAM (pulse-amplitude-modulation) of maize leaves infected by Colletotrichum graminicola. A and B, Middle segments of leaves 4 and 5, developing green islands and chlorotic spots, respectively. Parameters shown are Fv/Fm (maximal photosystem II [PS II] quantum yield), yield (effective PS II quantum yield) (at $79 \mu \mathrm{E} \mathrm{m}^{-2} \mathrm{~s}^{-1}$ ), and NPQ/4 (nonphotochemical quenching) (at $79 \mu \mathrm{E} \mathrm{m}^{-2} \mathrm{~s}^{-1}$ ). $\mathbf{C}$ and $\mathbf{D}$, Photographs and magnified views of yield at 4 days past inoculation from leaves with green islands and chlorotic spots, respectively. The color gradient provides a scale from 0 to $100 \%$ for assessing the magnitude of the parameters. Plants were 28 days old when inoculated. Bars represent $1 \mathrm{~cm}$. 
toms (Fig. 5B). The appearance of both symptoms strictly depended on the presence of the fungus, since we never observed any symptom that did not carry at least one appressorium. Symptoms that initiated from single appressoria were further assessed by fluorescence microscopy. In contrast to their surrounding senescent tissue, green islands retained chlorophyll autofluorescence (Fig. 5D and F). On the other hand, chlorotic spots lacked autofluorescence but were surrounded by tissue exhibiting chlorophyll autofluorescence (Fig. 5H and J). At 4 $\mathrm{dpi}$, the mycelium of the invading fungus, as visualized by
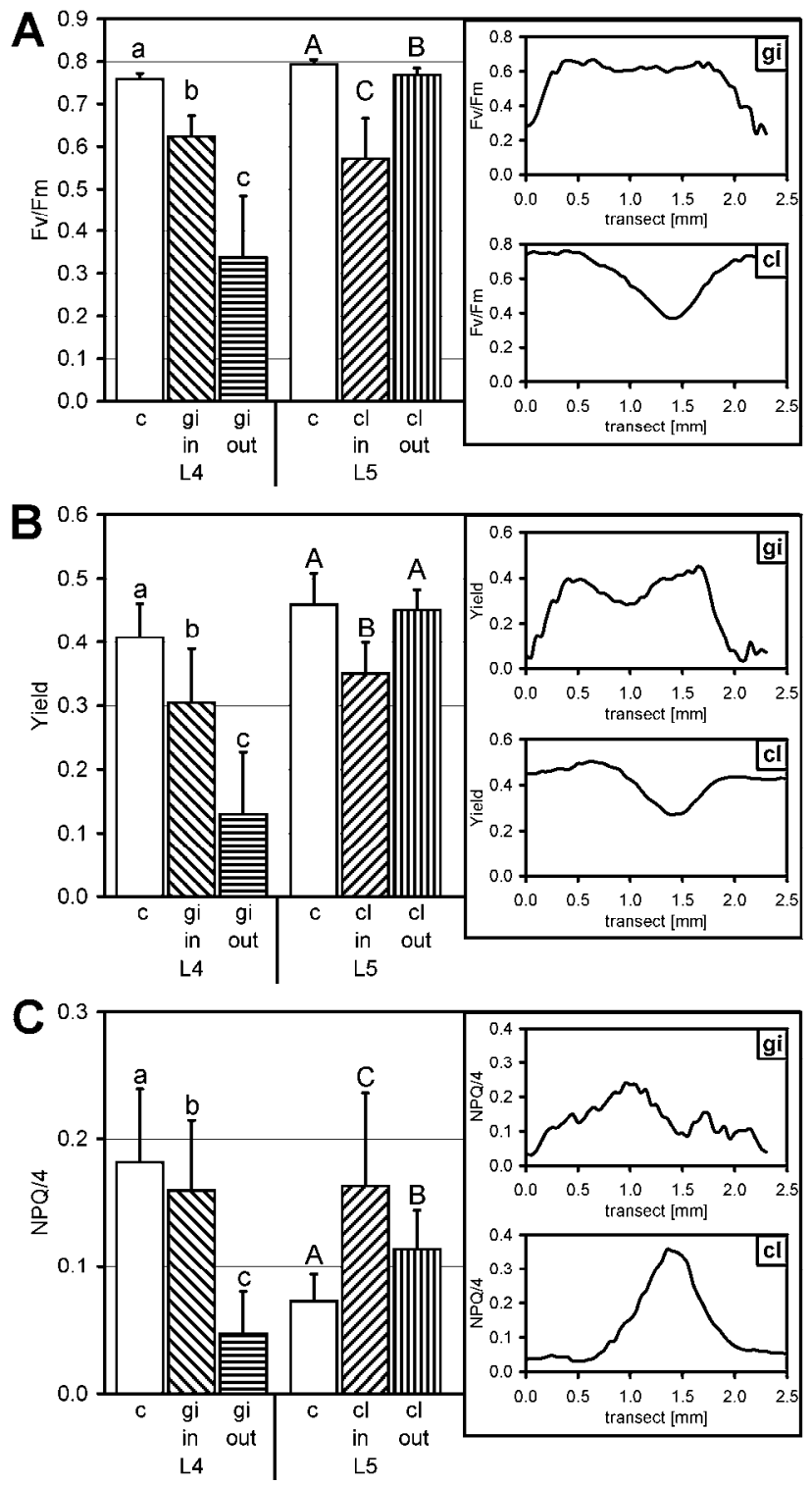

Fig. 4. Quantitative Imaging PAM (pulse-amplitude-modulation) of maize leaves infected by Colletotrichum graminicola. A, Fv/Fm (maximal photosystem II [PS II] quantum yield), B, yield (effective PS II quantum yield) (at $69 \mu \mathrm{E} \mathrm{m}^{-2} \mathrm{~s}^{-1}$ ), and $\mathbf{C}, \mathrm{NPQ} / 4$ (nonphotochemical quenching) (at $69 \mu \mathrm{E}$ $\mathrm{m}^{-2} \mathrm{~s}^{-1}$ ). Left sides of panels show means of three plants with standard deviations recorded for middle segments of leaves 4 and 5 with green islands and chlorotic spots. Solid white columns reflect mock-inoculated control leaves; hatched columns reflect infected leaves (gi-in, green islands, giout, tissues around green islands, cl-in, chlorotic spots, cl-out, tissues around chlorotic spots). Right sides of panels show transects recorded for a single representative symptom. Plants were 28 days old when inoculated and analysis was performed at 4 days past inoculation. The Holm-Sidak test evaluated variation between the respective control leaf, the areas within the symptom, and tissue surrounding the symptom. Different letters indicate significant differences at $P \leq 0.05$. constitutive green fluorescent protein (GFP) expression, did not extend to the edges of the symptom in $76.8 \%$ of the green islands (Fig. 5E and F) or in 54.3\% of the chlorotic spots (Fig. 5I and J). The central region of $78.4 \%$ of the green islands on leaf 4 had started to become necrotic at $4 \mathrm{dpi}$, as indicated by a brownish discoloration and also by the lack of autofluorescence (Figs. 5C and D and 1B).

Furthermore, we quantitatively assessed the differentiation of the GFP-expressing fungus and visual host cell responses by tracking individual infection events from the spore to the appressorium. This was performed for defined microscopical areas that were randomly distributed on inoculated leaves carrying either green islands or chlorotic spots. Inoculation density was at $1 \times 10^{6}$ spores per milliliter, so that the symptoms mostly arose from single appressoria. Not all spores that had landed on the leaf surface evoked symptoms under these conditions. On an older leaf (no. 4), 68.0\% of the spores had induced green islands at $4 \mathrm{dpi}$, whereas, at the same time on a younger leaf (no. 5), 96.7\% of the spores had induced chlorotic spots (not shown). Fluorescence microscopy revealed two different epidermal cell-wall reactions as host responses towards the infecting fungus that were visible when using either the GFP-longpass or the UV filterblocks. Using the GFP-longpass filter, the most common type of defense observed was yellow-orange cell-wall fluorescence, which may indicate the deposition of phenolic compounds (Nicholson and Hammerschmidt 1992). This response mostly occurred on young leaves within the areas of chlorotic spots $(26 \%)$ but rarely outside of them $(3.3 \%)$ and also rarely within the areas of green islands occurring on senescing leaves (4.0\%) (Fig. $5 \mathrm{M})$. When using the UV filterblock, the second type of cellwall reaction was observed that exhibited a bluish color (Fig. 50). It only occurred within the areas of chlorotic spots $(1.3 \%)$. The affected cells showed a discoloration of their walls under bright-field illumination and appeared collapsed, which may indicate rare hypersensitive-like responses (Fig. $5 \mathrm{~N})$. Interestingly, when host cell-wall reactions occurred at green islands, they remained confined to the initially penetrated cell (Fig. 5K and M). However, this seemed not to have prevented further growth of the fungus, since thick primary hyphae had invaded the surrounding epidermal cells (Fig. 5L) and autofluorescence was emitted from the interior of the leaf (Fig. 5M). At chlorotic spots in contrast, wall reactions occurred significantly $(P \leq 0.05)$ more frequently than at green islands in single infected cells and also spread out in $9.3 \%$ of all cases (Fig. $5 \mathrm{~K}$ and $\mathrm{O}$ ).

To compare the ingress of $C$. graminicola into deeper tissue layers, we embedded leaf segments showing green islands and chlorotic spots into epoxy resin. Thin sections were examined by light and electron microscopy (LM and EM, respectively) (Fig. 6A to K). At the level of LM, the tissue of green islands mostly appeared normal (Fig. 6A). The tissue did not collapse and hyphae were observed mainly in bundle-sheath cells (Fig. 6A through D), in which they grew longitudinally (Fig. 6C), apparently from cell to cell (Fig. 6D and G). The hyphae were surrounded by the plasma membrane of host cells (Fig. 6I). Hyphae contacting a host cell sometimes caused the formation of deposits at the periphery of the plant cell (Fig. $6 \mathrm{H}$ ). In contrast to the situation in senescing leaves, $C$. graminicola often caused a collapse of larger tissue areas in young leaves (Fig. 6E and F), leading to chlorotic spots. The regions flanking the collapsed areas appeared unaffected. Except for remnants of chloroplasts with starch grains and thylakoid membranes, no cellular organelles were found in the degenerated tissue (Fig. 6J and K). Because of the degree of degeneration, we were unable to unambiguously determine fungal structures in these regions. For that reason, we also stained hyphae with wheat germ agglutinin conjugated to 
Alexa Fluor 488. Hyphae were visualized in green islands (Fig. $6 \mathrm{~L}$ and $\mathrm{M}$ ) as well as in chlorotic spots (Fig. 6N and O). Fluorescence microscopy revealed that, after entering the leaf via epidermal cells (Fig. 6L), the fungus grew preferentially into the bundle sheath (Fig. 6L to O). In young leaves, it caused degeneration of mesophyll cells between two infected bundle sheaths
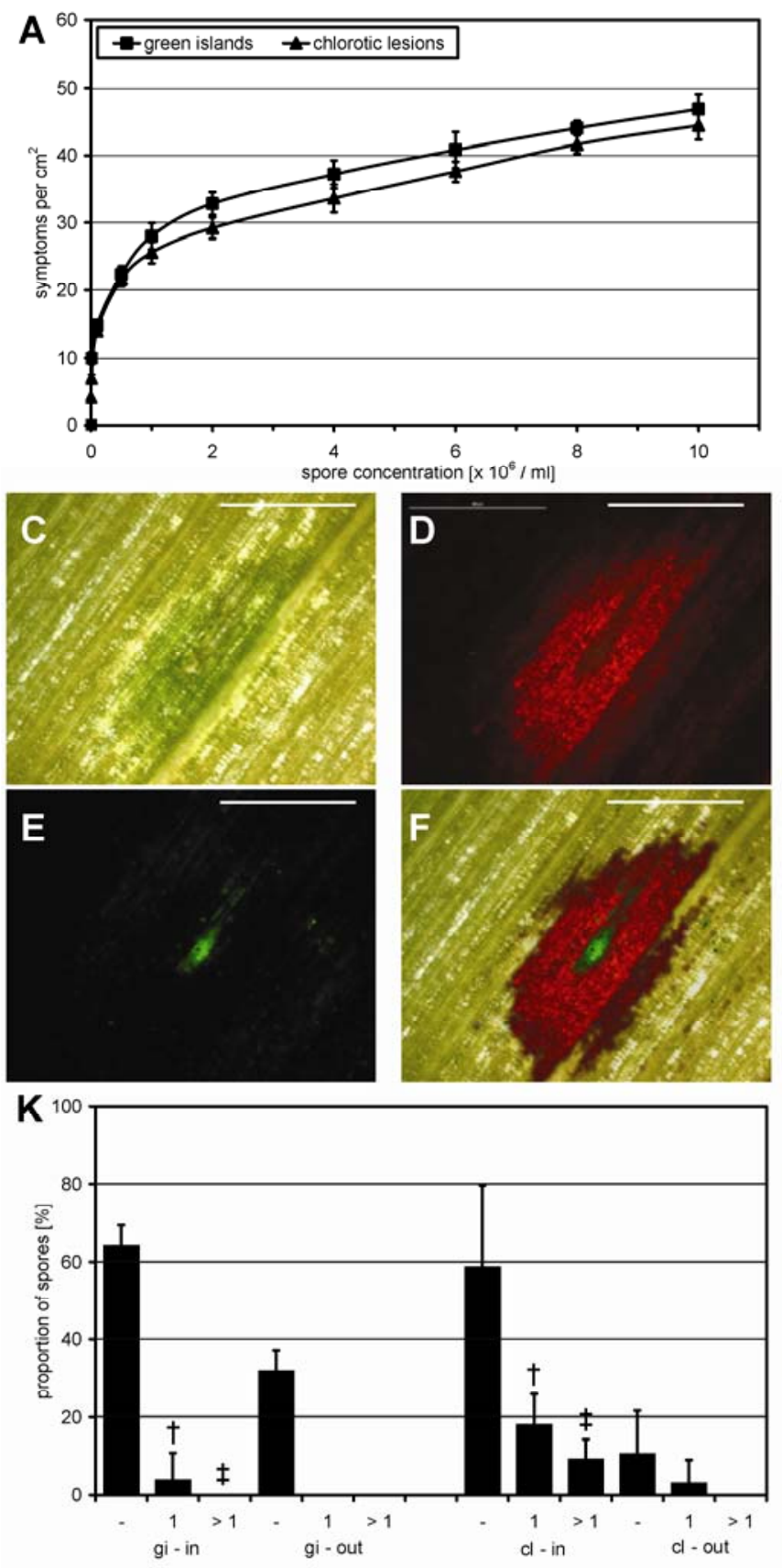

already at 3 dpi (Fig. $6 \mathrm{~N}$ ). It is noticeable that the majority of the collapsing cells were not infected at this stage. At $5 \mathrm{dpi}$, large regions had completely collapsed (Fig. 6O), which was also observed with LM (Fig. 6E). Hyphae were detected in the degenerated area, mostly in cells of the bundle sheath (Fig. $6 \mathrm{O}$ ) and rarely in other cell types.


Fig. 5. Symptom and fungal development and host defense reactions on maize leaves infected by Colletotrichum graminicola. A, Effect of inoculum density. To determine the symptom density, a molding $(0.5 \times 0.5 \mathrm{~cm})$ was randomly laid onto infected leaves, which was repeated 10 times per leaf. Data represent means of three plants, error bars indicate standard deviations. B, Numbers of appressoria within individual symptoms. Data represent means of 90 randomly chosen symptoms of each of three biological replicates, error bars indicate standard deviations. None of the variations between green islands and chlorotic lesions in A and B were found significant at $P \leq 0.05$ by the Holm-Sidak test. Micrographs of infection sites: $\mathbf{C}$ to $\mathbf{F}$, green island tissue, $\mathbf{G}$ to $\mathbf{J}$, chlorotic spot tissue, bars represent $100 \mu \mathrm{m}$. $\mathbf{C}$ and $\mathbf{G}$, Bright field microscopy, $\mathbf{D}$ and $\mathbf{H}$, fluorescence microscopy with longpass filter, and $\mathbf{E}$ and $\mathbf{I}$, fluorescence microscopy with a green fluorescent protein (GFP) filter, $\mathbf{F}$ and $\mathbf{J}$, overlays of C to E and G to I, respectively. K, Extent of host cell-wall reaction of epidermal cells differentiated by appressorial position. $-=$ no reaction, $1=$ single cell, $>1=$ more than one cell involved; gi-in, gi-out $=$ inside or outside of green islands, respectively, cl-in, cl-out $=$ inside or outside of chlorotic spots, respectively. Data represent means of 50 randomly chosen spores on each of three leaves with the respective symptom; error bars indicate standard deviations. Significant differences at $P \leq 0.05$ between leaves with green islands and leaves with chlorotic spots as detected by the Holm-Sidak test are marked by identical symbols on top of the corresponding pair. L, Differential interference contrast and $\mathbf{M}$, fluorescence microscopy with longpass filter showing a single epidermal cell with a yellow-orange wall reaction. $\mathbf{N}$, Bright field and $\mathbf{O}$, fluorescence microscopy with UV filter showing a bluish wall reaction involving three epidermal cells. Inoculation used 28-day-old plants and observation was at 4 days past inoculation. A to $\mathrm{B}, \mathrm{L}$ to $\mathrm{O}$ shows strain $\mathrm{CgM} 2$; $\mathrm{C}$ to $\mathrm{K}$ show strain CgGFP1-4. 



Fig. 6. Light and electron microscopy (LM and EM, respectively) of maize leaves infected by Colletotrichum graminicola. A to F, LM of sections stained with toluidine blue, $\mathbf{G}$ to $\mathbf{K}, \mathrm{EM}$, and $\mathbf{L}$ to $\mathbf{O}$, fluorescent micrographs of sections stained with WGA-Alexa Fluor 488. Green islands on older leaves (leaf 4 , left panels) and chlorotic spots on younger leaves (leaf 5, right panels). Bars represent: $\mathrm{A}, \mathrm{F}$, and $\mathrm{L}$ to $\mathrm{O}=50 \mu \mathrm{m} ; \mathrm{B}$ to $\mathrm{D}=20 \mu \mathrm{m} ; \mathrm{E}=100 \mu \mathrm{m} ; \mathrm{G}$ and $\mathrm{J}=2$ $\mu \mathrm{m} ; \mathrm{H}=1 \mu \mathrm{m}$; and I and $\mathrm{K}=0.5 \mu \mathrm{m}$. A, Cross section with arrow pointing to an infected bundle sheath. B, Magnification of A showing cross sectioned hyphae (arrowheads) in cells of the bundle sheath. C, Longitudinal section of infected bundle-sheath cells with longitudinally growing hyphae (arrows). D, Hypha (arrowhead) growing from one bundle-sheath cell into the next. E, Collapsed tissue of an infected younger leaf flanked by intact tissue. F, Magnification of collapsed tissue and neighboring intact tissue. G, Hypha (h) entering an adjacent cell. H, Hypha contacting a plant cell, causing formation of deposits (arrowhead) in the plant cell wall; $\mathrm{c}=$ chloroplast, $\mathrm{d}=$ dictyosome. I, Hypha within a plant cell covered by the plasma membrane of the host (arrowheads). J, Collapsed regions with remnants of the cytoplasm and chloroplasts (arrows). K, Chloroplasts in collapsed cells with thylakoid membranes and starch grains (asterisk). L, C. graminicola enters the leaf via the epidermis (arrow) and grows towards the bundle sheath (arrowheads). M, Hyphae in cells of the bundle sheath. N, Younger leaf at 3 days past inoculation (dpi). The tissue between two infected bundle sheaths (arrowheads) starts to collapse. $\mathbf{O}$, Collapsed tissue of a younger leaf at $5 \mathrm{dpi}$, containing hyphae in remnants of bundle sheath (arrowheads). 
Expression of maize genes encoding proteins involved in photosynthesis, senescence, and source-sink relationship.

The experiments described above indicated that fungal infection affected the progress of senescence and photosynthetic activity. To substantiate these findings at the molecular level, we used quantitative reverse transcription-polymerase chain reaction (qRT-PCR) to determine the relative transcript levels of selected maize genes exactly at the infection sites. RNA preparations originated from pooled tissue samples that were collected at $4 \mathrm{dpi}$ from green islands excised from infected leaf 4 , chlorotic spots from leaf 5 , and the correspondingly excised ring-shaped tissues that surrounded these symptoms. For further assessments, RNA preparations isolated from whole infected leaves 4, 5, and 6 and corresponding mock-inoculated controls were also included in these experiments. Genes analyzed represented markers for senescence (He et al. 2005; McLaughlin and Boyer 2004), photosynthesis (Hahnen et al. 2003), and source-sink status (McLaughlin and Boyer 2004; Roitsch et al. 2003) (Supplementary Table S1).

Transcript abundance of genes that were considered as markers of senescence, such as the genes encoding proteases see1, see2a, see $2 b$, ccp1, and lipase pld1, was analyzed. Only the transcript levels of see 1 , see $2 b$, and ccpl increased with leaf age in controls (Supplementary Fig. S1D to F). Those of see $2 a$ and pldl were relatively constant in the control leaves and were thus excluded from further analyzes (not shown). When whole infected leaves of different ages were compared with their respective controls, the transcript levels of seel and $c c p l$ were generally lower. For see $2 b$, a decreased expression as a result of infection was obvious for leaf 5. In RNA preparations from both green islands and chlorotic spots, the transcript levels of seel and ccpl were reduced as compared with the whole infected leaves. The differences between the centers and the surroundings of green islands and chlorotic spots were minor, except for $c c p 1$, which was more reduced in the center of green islands. Thus, the results from see 1 and ccpl supported the notion of a pathogen-induced delay of senescence that occurred in green islands and chlorotic spots.

To monitor the expression of two genes known to encode the small subunit of ribulose-1,5-biphosphate carboxylase in maize ( $R b c S 1$ and $R b c S 2)$ published gene-specific primer pairs were employed (Hahnen et al. 2003). In addition, we analyzed the transcript levels of genes encoding chlorophyll a/b-binding protein, also called PS II subunit CP29 (cp29), and the C4-specific isoforms of malic enzyme ( $m e l)$ and PEP carboxylase (pepl) (Hahnen et al. 2003). Expression of all these genes generally decreased with age, which corresponded to the progress of senescence (Fig. 1A) and the reduction of photosynthetic activity expressed as ETR (Fig. 2D and E). Infected leaves, analyzed as a whole, exhibited for all genes except mel lower transcript levels when compared with the respective control leaves, which paralleled enhanced reductions of ETR observed after infection (Fig. 2D and E). Transcript levels of mel were generally elevated in whole infected leaves. For most of these genes, the differences between the infected and control leaves were largest for the oldest leaf. Transcript levels were decreased in most tissue samples that were excised from both symptoms when compared with the respective whole infected leaves. Transcript levels of all five genes were lower inside chlorotic spots than outside, whereas in green islands, except for pepl, the opposite trend was seen.

The expression of specific host invertases increased in plants infected by several pathogens, implying effects of infection on one or both the source-sink status the induction of host defense (Berger et al. 2007; Biemelt and Sonnewald 2006; Roitsch et al. 2003). We analyzed whether or not any of the six genes known to encode invertases in maize (incw1, incw2, incw3, incw4, ivrl, and $i v r 2)$ were differentially expressed after infection with $C$. graminicola. We were not able to detect any reaction product for incw 2 and incw3, even after 50 cycles of qRT-PCR in ethidium bromide-stained agarose gels (not shown). Since the cycle threshold values for these genes also reflected very low background expression levels in the analyzed samples, incw 2 and incw3 appeared to be not significantly expressed in leaves, as previously reported (Kim et al. 2000). The transcript levels of the other four genes generally decreased with age in the noninfected controls, reflecting the transition from a young to a senescent leaf. Infected leaves exhibited rather specific responses for the expression of these invertase genes. In comparison to the respective noninfected controls, the transcript levels of incwl and $i v r l$ were increased in whole old leaves but were decreased in young leaves. For the other two genes, incw 4 and ivr2, a clear difference between whole infected and control leaves was only observed for incw4 in the youngest leaf analyzed (no. 6). Compared with the whole infected leaf, the centers of both green islands and chlorotic spots exhibited higher transcript levels of incwl and ivr2. In the center of green islands, incwl was induced by a factor of 70 , when compared with the noninfected control. In contrast, the transcript levels of incw 4 and ivrl were lower in tissues excised from green islands and chlorotic spots. Notably, the inclusion of the excised infection sites allowed uncovering a downregulation of incw 4 and an upregulation of $i v r 2$ expression just at the sites of fungal infection, which would have remained undetected when analyzing only whole infected leaves.

\section{DISCUSSION}

Previously, pathogenesis of $C$. graminicola on maize leaves was studied using young plants for inoculation. In the field however, the fungus initiates disease from plant debris. As spores are typically dispersed by rain drops splashing onto lower leaves, infections occurring on host tissue close to or at senescence may be of importance with respect to epidemiology. Therefore we have comparatively investigated at high spatial resolution pathogenesis and host responses occurring on senescing and on young leaves. We show that the fungus is able to infect leaves at early senescence causing green islands, a symptom that is novel for this pathosystem. This symptom is in strong contrast to the anthracnose symptom previously described for mature leaves (Bergstrom and Nicholson 1999; Mims and Vaillancourt 2002). Depending on the age of the leaf, $C$. graminicola can not only provoke two different symptoms but also has distinct effects on host defense reactions, progress of senescence, photosynthesis, and the source-sink status.

C. graminicola is a pathogen that features high flexibility when infecting its host. Recently, evidence has been provided that this fungus not only infects leaves and stalks but also the roots of maize, from which it can spread systemically to upper plant organs in which it may cause secondary symptoms (Sukno et al. 2008). Typical infections on mature leaves result in symptoms that become visible initially as yellowish chlorotic spots that progress to anthracnoses. Fungal and symptom development has been extensively studied for infections leading to anthracnoses (Bergstrom and Nicholson 1999; Mims and Vaillancourt 2002). By using for inoculations older maize plants in which the lower leaves were at the border of or had initiated senescence, we discovered a different symptom, i.e., green islands, which displays a new facet of the intricate interaction between C. graminicola and maize. As reported previously, the susceptibility of the maize cultivar Gaspe Flint, expressed as lesion length, increased with the age of the infected leaf (Leonard and Thompson 1976). Although plants of various ages were tested in that report, green islands were not mentioned. Previ- 
ously, green islands had been described for several other pathogens, including obligate biotrophic and necrotrophic fungi, and furthermore, certain viruses and insects (Walters et al. 2008). Two types of green islands have been distinguished, so called green bionissia and green necronissia (Walters et al. 2008). The former are typically observed in infections involving obligate biotrophs, the latter are found in some necrotrophic, toxin-producing pathogens. Green islands formed by hemibiotrophs are found in both categories, which probably results from the heterogeneity in pathogenesis. Green bionissia has been defined as a symptom in which the cells of the fungus and the host are alive, whereas green necronissia describes a symptom in which only pathogen cells are alive (Walters et al. 2008). Based on these definitions, the green islands induced by C. graminicola on senescing maize leaves resemble green bionissia. Eventually, the central epidermal cells of the symptom become necrotic, whereas the bundle sheath and the mesophyll cells that are invaded by the fungus initially appear not to be damaged. In contrast to the limited damage of host tissue during the emergence of green islands on senescing leaves, the cell collapse visible at the same time at chlorotic spots on younger leaves extends through all tissue layers.

C. graminicola does not randomly proliferate through the mesophyll when growing out of the epidermal layer during the first four days of the infection. Rather, the fungus grows towards the bundle sheath, from which it further spreads longitudinally through the leaf. In the interior of the leaf, most hyphae assemble in bundle-sheath cells, some also in mesophyll cells. Our microscopy on cross sections confirms a report that showed surface views of an infected maize leaf in which a GFP-expressing strain of $C$. graminicola grew in bundle sheaths (Venard and Vaillancourt 2007b), which were shown to be used for hyphal spreading in stalk infections (Tang et al. 2006; Venard and Vaillancourt 2007a), and evidently, the same applies for leaf infections as well. During pathogenesis, the fungus sometimes seems to be recognized, as indicated by host cell-wall epifluorescence that may result from the accumulation of lignin and other phenolic substances (Hammerschmidt and Nicholson 1977; Nicholson and Hammerschmidt 1992; Nicholson et al. 1989). Such cell-wall reactions are more frequent and extended at chlorotic spots than at green islands. When occurring in the latter, they remain confined to the initially penetrated cell. Host cell-wall papillae, which have been previously reported to occur in the maize cultivar Mo940 after inoculation with $C$. graminicola (Mims and Vaillancourt 2002), were very rarely found in our study, i.e., in less than $1 \%$ of the appressorial infection sites. It is possible that this phenomenon varies with the host cultivar used or the growth and inoculation conditions.

Besides these distinct effects on symptom development and host defense reactions, $C$. graminicola also affects host senescence and photosynthesis. In addition to a globally accelerated senescence comprising the whole leaf, a differential response occurs locally at infection sites, depending on the age of the leaf. On young and mature leaves, chlorotic spots associate with tissue collapse and a locally reduced photosynthesis. The visible loss of chlorophyll is not necessarily linked to developmental leaf senescence but can also result from pseudosenescence (Ougham et al. 2008). In the latter, chlorophyll can disappear, for example as a consequence of oxidative damage occurring during pathogenesis. Thus, chlorotic spots probably do not reflect local developmental senescence. In contrast, on lower senescing leaves, green islands are sites at which developmental senescence and the decline of photosynthesis are locally delayed. It may be critical that infected host cells remain alive during the biotrophic phase of $C$. graminicola, since their premature death could prevent the progress of infection. A de- lay of leaf senescence is thus important during this stage. The occurrence of green islands is linked to early leaf senescence, since leaves at late stages of senescence do not re-green when inoculated with $C$. graminicola (not shown).

We performed qRT-PCR experiments to demonstrate, on the molecular level, a modification of host physiology as a result of fungal infection. The expression of see 1 , see $2 b$, and ccpl, which encode cysteine proteases, follow trends in noninfected controls, as anticipated for senescence markers (Donnison et al. 2007; He et al. 2005; McLaughlin and Boyer 2004; Smart et al. 1995), i.e., their transcript abundance increases with age. Remarkably, infection led to reduced expression of seel and ccpl and, to a lesser degree, see $2 b$, which underscores the possibility that $C$. graminicola may interfere with the progress of senescence.

Previously, green islands have been analyzed for photosynthesis in other pathosystems, mostly obligate biotrophic rust and mildew fungi (Walters et al. 2008; Wingler and Roitsch 2008). Similar to the findings in our study, photosynthesis was typically found increased when infected areas were compared with noninfected areas of a senescing leaf but decreased when compared with noninfected control leaves. Accordingly, as a consequence of infection, we anticipated some decrease of transcript levels of genes encoding proteins involved in photosynthesis. However, we found that the transcript levels of the genes encoding the C4specific isoforms of PEP carboxylase, PS II subunit CP29, and two isoforms of the small subunit of Rubisco were strongly reduced in infected leaves of either symptom. Nevertheless, in support of the results described above (Figs. 3 and 4), local transcript levels exhibited opposing trends when green islands are compared with chlorotic spots, which correlates with a retardation of downregulation of photosynthetic activities in the green islands. However, changes in transcript levels of photosynthesisrelated genes may not be the main reason for alterations in photosynthetic activities. In addition to transcriptional regulation, post-transcriptional and post-translational processes may also mediate the transient delay of the decline of photosynthetic activity. For Rubisco (Patel and Berry 2008) and PEPC (Chollet et al. 1996; Izui et al. 2004), a complex regulation beyond the transcriptional level is well established.

In a few fungal pathosystems, the reduction of transcript levels of genes encoding proteins that are involved in photosynthesis has been documented. Examples are the genes $R b c S$ and cap (=cp29) in the biotrophic interactions of barley with Blumeria graminis (Swarbrick et al. 2006) and of Arabidopsis thaliana with Albugo candida (Chou et al. 2000) that were down-regulated after infection. Furthermore, a microarray analysis for maize revealed that expression of many genes involved in photosynthesis was reduced after an infection with the biotrophic Ustilago maydis (Doehlemann et al. 2008). It was previously shown in maize that $R b c S 1$ is preferentially expressed in mesophyll cells of tissues performing C3 photosynthesis, whereas $R b c S 2$ transcripts accumulate in bundlesheath cells of $\mathrm{C} 4$ tissues by using the same specific primers as in our study (Hahnen et al. 2003). The ratio of the relative transcript levels of $R b c S 1$ to $R b c S 2$ was found to be higher in tissues performing $\mathrm{C} 3$ than in those performing C4 photosynthesis. According to these results, there would have been an increase in the ratio of $R b c S 1$ to $R b c S 2$ transcripts if there had been a switch from $\mathrm{C} 4$ to $\mathrm{C} 3$ photosynthesis in leaves infected by $C$. graminicola. However, this ratio did not increase after infection but, rather, decreased, and a prevention of a switch from $\mathrm{C} 3$ to $\mathrm{C} 4$ photosynthesis, as reported for maize leaves infected by $U$. maydis (Horst et al. 2008), has not been detected for C. graminicola in our studies.

In addition to the diverging effects on symptom development, host defense reactions, host senescence, and photosyn- 
thesis, $C$. graminicola also affects the source-sink status in the host. At infection sites, pathogens create new local sinks that globally compete with distant sink organs of the host and locally with host cells carrying out costly defense reactions (Biemelt and Sonnewald 2006; Wingler and Roitsch 2008). In mature leaves, the products of photosynthesis are, in part, transformed to sucrose, exported to the apoplast, loaded to the phloem, and transported to sink organs. In contrast, when $C$. graminicola infects a senescing leaf, it encounters an environment that undergoes a transition with respect to the quality and quantity of putative substrates. The supply with carbohydrates may be more limited in green islands, in which neighboring cells undergo senescence and shut down photosynthesis. The local continuation of photosynthesis at green islands may support C. graminicola with carbohydrates during a critical early phase of pathogenesis.

Cell-wall invertases are important to determine sink strength in an infected leaf. Increased cleavage rates of apoplastic sucrose will lead to a reduced transport of carbohydrates into distant sink organs and will increase locally their availability to support pathogens and host defenses (Roitsch et al. 2003). We took advantage of the discovery that $C$. graminicola induces two different and confined symptoms at the same time on different leaves to analyze the expression of all known maize invertases at an as-yet-unprecedented spatial resolution. Of six genes analyzed, encoding four cell wall-bound and two vacuolar invertases, incwl exhibited the most remarkable change in transcript abundance after infection. Within the area of green islands, incw 1 transcript levels increased 70-fold but only 24-fold within yellow spots, supporting the notion that local carbon availability may be more critical in green islands. At short distances around both symptoms, incwl transcript levels dropped considerably, thus indicating local gradients. In other fungal pathosystems, the activity of cell-wall invertases and the expression of host genes encoding these enzymes typically increase after infection (Biemelt and Sonnewald 2006; Wingler and Roitsch 2008). Furthermore, the involvement of fungal invertase in the establishment of a local sink has been suggested for the obligate biotrophic rust fungus Uromyces fabae (Voegele et al. 2006), the facultative smut fungus $U$. maydis (Horst et al. 2008), and the necrotrophs Sclerotinia sclerotiorum (Jobic et al. 2007), and Botrytis cinerea (Ruiz and Ruffner 2002). It was proposed that, in the interactions of $S$. sclerotiorum with sunflower and of $U$. maydis with maize, fungal and not host invertases are most important to supply the pathogen with hexoses. Whether or not there is a major fungal contribution to local invertase activity, $C$. graminicola should be able to import and utilize the resulting hexoses, as previously suggested for $U$. fabae (Voegele et al. 2001) and S. sclerotiorum (Jobic et al. 2007).

Our study provides evidence, gained at a high spatial resolution, for a model proposing that fungal infection locally causes an increase in host invertase activity, leading to the accumulation of hexoses. High concentrations of hexoses have been shown to act as a signal to repress the expression of photosynthetic genes (Chou et al. 2000; Scholes et al. 1994). Furthermore, our results are in agreement with experiments in transgenic tobacco showing that the expression of extracellular invertase under the control of a senescence-induced promoter caused a delay of senescence and that green islands result from locally increased invertase activity (Balibrea Lara et al. 2004). It is thus possible that the green islands caused by $C$. graminicola result from sugar signals that are generated by fungus-induced locally enhanced plant invertase activity. It will remain to be shown if the creation of a new local sink established by the fungus is sufficient to control, in the host, the state of senescence, photosynthetic activity, and the resulting green islands.
Alternatively, the fungus may interfere with the physiology of its host in a more complex manner.

\section{MATERIALS AND METHODS}

\section{Plant and fungal materials.}

The maize cultivar Mikado (KWS SAAT AG, Einbeck, Germany) was grown in the greenhouse in steamed garden soil, in pots with a diameter of $14 \mathrm{~cm}$ and a height of $17 \mathrm{~cm}$, at temperatures varying between $22^{\circ} \mathrm{C}$ and $30^{\circ} \mathrm{C}$; the humidity was not controlled. Four seeds per pot were sown, pots were distributed in a randomized manner and their positions were changed once a week.

Colletotrichum graminicola (Ces.) G.W. Wilson wild-type strain M2 and the strain GFP1-4 that resulted from an ectopic integration of plasmid gGFP (Maor et al. 1998) in strain M2 (not shown) were cultivated on oatmeal agar at $23^{\circ} \mathrm{C}$ under illumination with black light (TLD36W/08; Philips, Hamburg, Germany), to induce conidiation. Compared with wild type, strain GFP1-4 exhibited no difference in respect to vegetative growth, sporulation, and virulence. To produce inoculum for infection assays, spores from 14-day-old fungal cultures were suspended in $0.01 \%$ (vol/vol) Tween 20 . For standard infection assays, suspensions were adjusted to a concentration of $1 \times 10^{6}$ spores per milliliter, if not stated otherwise.

\section{Infection assays.}

Two days before inoculation, plants were taken from the greenhouse and were incubated in an environmentally controlled growth chamber (model AR-75L; Percival Scientific, Boone, IA, U.S.A.). Illumination was for $16 \mathrm{~h}$ per day at $200 \mu \mathrm{E} \mathrm{m}{ }^{-2}$ $\mathrm{s}^{-1}$ at soil level, $50 \%$ humidity, and $25^{\circ} \mathrm{C}$. The dark period was set to $70 \%$ relative humidity (r.h.) and $20^{\circ} \mathrm{C}$. After inoculation, the growth chamber was run at $100 \%$ r.h. and $25^{\circ} \mathrm{C}$ for $24 \mathrm{~h}$, keeping the day and night light cycle unchanged. Afterwards, the previous conditions were used for the rest of the incubation period. For inoculation, each plant was sprayed with $1.7 \mathrm{ml}$ of a freshly prepared spore suspension.

\section{Chlorophyll fluorescence imaging.}

The Imaging PAM chlorophyll fluorometer and the software ImagingWIN version 2.14 (both Heinz Walz GmbH, Effeltrich, Germany) were employed to determine photosynthetic parameters from infected and control maize leaves. An integrated CCD camera enabled recording highly resolved digital images of the emitted fluorescence.

Plants were adjusted for $10 \mathrm{~min}$ in the dark prior to measurement, and then, a detached leaf was clamped onto the holder. The distance between the leaf surface and the CCD camera was set to $7 \mathrm{~cm}$, resulting in a visible area of $24 \times 32 \mathrm{~mm}$. The other variables were as follows: measuring light with intensity $=2$, frequency $=1$, gain $=7$, damping $=2$; saturation pulse with intensity $=10$ and width $=8$. Each recording started by determining the dark fluorescence parameter $\mathrm{F}_{0}$. Subsequently, a saturating light pulse was applied to determine the maximal fluorescence parameter Fm, which is used by the software to calculate the maximal PS II quantum yield $\left(\mathrm{Fv} / \mathrm{Fm}=\left(\mathrm{Fm}-\mathrm{F}_{0}\right) / \mathrm{Fm}\right)$. The dissipation of absorbed energy by nonphotochemical processes is minimal when a light pulse is applied after a phase of dark adaptation, thus allowing the measurement of Fm. In the presence of actinic illumination ranging from 9 to $1,209 \mu \mathrm{E} \mathrm{m}^{-2} \mathrm{~s}^{-1}$, the current fluorescence yield $(\mathrm{Ft})$ and the maximum lightadapted fluorescence $\left(\mathrm{Fm}^{\prime}\right)$ were measured to calculate the effective PS II quantum yield (Y(II) $\left.=\left(\mathrm{Fm}^{\prime}-\mathrm{Ft}\right) / \mathrm{Fm}^{\prime}\right)$. This parameter is suited to reveal variation in photosynthetic efficiency when actinic light is used. In addition, the nonphotochemical quenching $\left(\mathrm{NPQ}=\left(\mathrm{Fm}-\mathrm{Fm}^{\prime}\right) / \mathrm{Fm}\right)$ was determined, giving 
the proportion of absorbed light energy that is not used for photosynthetic electron transport (Bilger and Bjorkman 1990; Oxborough 2004). NPQ/4 is NPQ divided by four to allow for a display in a color code ranging from 0 to $100 \%$. In order to measure changes in photosynthetic electron transport in the leaves, the relative ETR was determined $(\mathrm{ETR}=0.5 \times \mathrm{Y}(\mathrm{II}) \times$ PAR $\times \mathrm{c}$ ), which includes the value for the known flux of photosynthetically active radiation (PAR) and a coefficient c, describing the absorption of PAR by PS II (0.84) (Schreiber 1994).

For quantitative analyses of whole leaves, the software used 100 areas of interest (AOI) of $3 \mathrm{~mm}^{2}$ that were randomly distributed over each leaf segment measured. For each variant, three individual plants were used and the respective results were averaged. For quantitative analyses of individual symptoms, 150 AOI of $0.2 \mathrm{~mm}^{2}$ each were used to determine photosynthetic parameters in green islands, chlorotic spots, and the corresponding surrounding areas. For each variant, three plants were used and the results were averaged.

\section{Microscopy.}

For fluorescence microscopy of whole-leaf segments, we used a Nikon Eclipse 600 microscope (Nikon GmbH, Düsseldorf, Germany) that was equipped with the following filter blocks (all from Nikon): GFP-block (Ex 480/40, DM 505, BA 535/50), longpass block for detection of chlorophyll autofluorescence (Ex 460-500, DM 505, BA 510), and UV-block for detection of fluorescence at plant cell walls (Ex 330-380, DM 400, BA 420). Digital images were recorded with a CCD-1300 camera (VDS Vosskühler GmbH, Osnabrück, Germany) and were archived and processed with software packages Lucia G 4.71 and NIS-Elements D 2.30 (both Nikon GmbH, Düsseldorf, Germany).

For transmission and LM, leaf segments were fixed with $3 \%$ (vol/vol) glutaraldehyde (Sigma, Taufkirchen, Germany) in

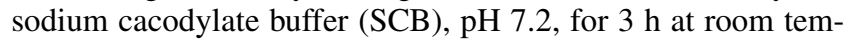
perature, and then, washed with $\mathrm{SCB}$, postfixed with $1 \%$ (wt/vol) osmium tetroxide (Roth, Karlsruhe, Germany) in SCB, dehydrated in a graded ethanol series, and embedded in epoxy resin (Spurr 1969). The material was sectioned with an ultramicrotome S (Leica, Bensheim, Germany). Semithin sections $(1 \mu \mathrm{m})$ were stained with $1 \%$ (wt/vol) toluidine blue and were observed with an Axioskop 20 light microscope (Zeiss, Jena, Germany). Ultrathin sections $(80 \mathrm{~nm})$ were transferred to coated copper grids and were poststained with uranyl acetate and lead citrate. The sections were observed with an EM 900 transmission electron microscope (Zeiss SMT, Oberkochen, Germany) at an acceleration voltage of $80 \mathrm{kV}$. Electron micrographs were taken with a slow scan camera (Variospeed SSCCD camera SM-1k-120, TRS, Moorenweis, Germany).

For histochemical detection of fungal structures, leaf segments were fixed with 3\% (vol/vol) paraformaldehyde (Sigma) in phosphate buffered saline (PBS) for $3 \mathrm{~h}$ at room temperature, were washed with PBS, and were dehydrated in a graded ethanol series. Subsequently, the samples were infiltrated stepwise with PEG 1500 (Merck-Schuchhardt, Hohenbrunn, Germany) at $48^{\circ} \mathrm{C}$ and were embedded in PEG 1500 . Sections ( 3 $\mu \mathrm{m})$ were transferred to poly-L-lysine-coated slides, were washed with PBS, and were incubated with wheat germ agglutinin-conjugated Alexa Fluor 488 (Molecular Probes, Eugene, OR, U.S.A.) for $2 \mathrm{~h}$. After rinsing with PBS, the sections were enclosed with Citifluor-glycerol (Plano, Wetzlar, Germany) and were observed with an Axioskop 20 (Zeiss), using filter set 09 (450-490/510/515).

\section{Isolation of RNA and qRT-PCR.}

Total RNA was isolated from maize leaves that were inoculated with strain CgM2 28 days after sowing and harvested 4 days later, $6 \mathrm{~h}$ after beginning of the light period. Whole leaves 4,5 , and 6 were harvested from six individual plants, were pooled, and were immediately frozen in liquid nitrogen. In addition, hundreds of tissue samples ( $1 \mathrm{~mm}$ in diameter) carrying green islands on leaf 4 and chlorotic spots on leaf 5 were excised with a canula, were frozen in liquid nitrogen, and were stored at $-80^{\circ} \mathrm{C}$. Tissues that surrounded and excluded these symptoms were excised with a cork borer ( $5 \mathrm{~mm}$ in diameter). Isolation of total RNA was performed as described (Krijger et al. 2008). RNA isolation for variants representing whole leaves was performed on three independent pools, each comprising samples of six plants. These pools originated from inoculations performed on three successive weeks. RNA isolation from excised tissue samples was carried out on pools that originated from several independent inoculations.

Chemicals, equipment, and the procedures to assess the specificity and to optimize the reaction conditions for qRTPCR were as described earlier (Krijger et al. 2008). Also serial qRT-PCR analyses followed these procedures, except that 10 ng of total RNA were used as template. In total, three repeated data sets were generated, each analyzing 10 variants, i.e., leaves 4,5 , and 6 of infected and control plants, excised tissues of green islands and chlorotic spots, plus their surrounding tissues. After melting curve analysis, $6 \mu \mathrm{l}$ of the final reaction products of all qRT experiments were loaded onto $2 \%$ (wt/vol) agarose gels, to control for amplification of nonspecific bands. For each target that we could amplify, a representative band was excised from the gel. The DNA was purified and sequenced as reported (Krijger et al. 2008). In all cases, the anticipated sequence was obtained.

Whenever possible, we designed the primers to include an intron to control for the possibility that maize genomic DNA may have contaminated the RNA preparations used for qRTPCR and, thus, may have produced false signals. For example, primers targeting the actin 1 gene of maize yielded, with maize genomic DNA as a template, the anticipated fragment including the intron. In contrast, all maize RNA preparations produced only the correspondingly smaller, spliced fragment. There was no apparent cross-reactivity when pure fungal DNA or RNA was used as template. As an additional control, we used primers targeting histone $\mathrm{H} 3$ of $C$. graminicola (Krijger et al. 2008). These analyses confirmed that contaminating DNA was not detectable in the RNA preparations from infected tissues and that RNA preparations from noninfected controls were devoid of contaminating fungal templates.

We used sigmoidal curve fitting to optimize quantitative analyses of qRT-PCR data (Liu and Saint 2002). The software SigmaPlot version 11 (Systat Software GmbH, Erkrath, Germany) was used to determine the initial fluorescence $\left(R_{0}\right)$ of each reaction, which relates to the initial amount of the target in the sample. For each of the three data sets generated and for all genes analyzed, the $\mathrm{R}_{0}$ values were expressed relative to that of the smallest value, which was set to 1 . These adjusted $\mathrm{R}_{0}$ values were then used to calculate the corresponding arithmetic means. Next, we applied the software geNORM (Vandesompele et al. 2002) to calculate the gene-stability measures (M) for putative housekeeping genes. Those encoding actin 1 and polyubiquitin 1 had unacceptable gene-stability measures $(\mathrm{M}>0.7)$ and were, therefore, excluded. However, the genes encoding $\alpha$-tubulin 3, $\gamma$-tubulin 1, and histone H2B had acceptable scores $(\mathrm{M} \leq 0.5)$. The arithmetic means of the adjusted $R_{0}$ values of these three housekeeping genes were used to calculate combined geometric means (Vandesompele et al. 2002). The arithmetic means of the adjusted $R_{0}$ values of the target genes were divided by these geometric means, to normalize for putative variations in RNA quality and quantity. The effect of this procedure became evident when the geomet- 
ric means of the relative transcript levels of the three housekeeping genes were compared before and after normalization. Finally, a second relativization was carried out to adjust the smallest value again to 1 .

\section{Statistical analyses.}

In all analyses except that shown in Figure 2F, two-way analysis of variance (ANOVA) evaluated whether different experimental groups were affected by two different treatments. For the analysis shown in Figure 2F, three-way ANOVA was performed. In cases in which significant differences were detected $(P \leq 0.05)$, the Holm-Sidak test was applied as a post hoc test, either for pairwise comparisons or comparisons versus a control group, depending on the experimental design. Values of $P \leq 0.05$ were considered significant. All statistical analyses used the software SigmaStat version 3.1 (Systat Software GmbH, Erkrath, Germany).

\section{ACKNOWLEDGMENTS}

We thank K. Sommerfeld and S. Jahn for technical assistance, E. Vollmer for greenhouse services, and J.-J. Krijger for help with qRT-PCR. This work was supported by a Deutsche Forschungsgemeinschaft grant provided in the framework of the SFB 648 (projects A5 to S. G. R. Wirsel and H. B. Deising, and Z1 to G. Hause).

\section{LITERATURE CITED}

Amusa, N. A. 1994. Production, partial purification and bioassay of toxic metabolites of three plant-pathogenic species of Colletotrichum in Nigeria. Mycopathologia 128:161-166.

Balibrea Lara, M. E., Gonzales Garcia, M.-C., Fatima, T., Ehness, R., Lee, T. K., Proels, R., Tanner, W., and Roitsch, T. 2004. Extracellular invertase is an essential component of cytokinin-mediated delay of senescence. Plant Cell 16:1276-1287.

Bechinger, C., Giebel, K. F., Schnell, M., Leiderer, P., Deising, H. B., and Bastmeyer, M. 1999. Optical measurements of invasive forces exerted by appressoria of a plant pathogenic fungus. Science 285:1896-1899.

Berger, S., Sinha, A. K., and Roitsch, T. 2007. Plant physiology meets phytopathology: Plant primary metabolism and plant pathogen interactions. J. Exp. Bot. 58:4019-4026.

Bergstrom, G. C., and Nicholson, R. L. 1999. The biology of corn anthracnose-knowledge to exploit for improved management. Plant Dis. 83:596-608.

Biemelt, S., and Sonnewald, U. 2006. Plant-microbe interactions to probe regulation of plant carbon metabolism. J. Plant Physiol. 163:307-318.

Bilger, W., and Bjorkman, O. 1990. Role of the xanthophyll cycle in photoprotection elucidated by measurements of light-induced absorbency changes, fluorescence and photosynthesis in leaves of Hedera canariensis. Photosyn. Res. 25:173-185.

Bonfig, K. B., Schreiber, U., Gabler, A., Roitsch, T., and Berger, S. 2006. Infection with virulent and avirulent $P$. syringae strains differentially affects photosynthesis and sink metabolism in Arabidopsis leaves. Planta 225:1-12.

Chollet, R., Vidal, J., and O'Leary, M. H. 1996. Phosphoenolpyruvate carboxylase: A ubiquitous, highly regulated enzyme in plants. Annu. Rev. Plant Physiol. Plant Mol. Biol. 47:273-298.

Chou, H.-M., Bundock, N., Rolfe, S. A., and Scholes, J. D. 2000. Infection of Arabidopsis thaliana leaves with Albugo candida (white blister rust) causes a reprogramming of host metabolism. Mol. Plant Pathol. 1:99113.

Doehlemann, G., Wahl, R., Horst, R. J., Voll, L. M., Usadel, B., Poree, F., Stitt, M., Pons-Kuhnemann, J., Sonnewald, U., Kahmann, R., and Kamper, J. 2008. Reprogramming a maize plant: Transcriptional and metabolic changes induced by the fungal biotroph Ustilago maydis. Plant J. 56:181-195.

Donnison, I. S., Gay, A. P., Thomas, H., Edwards, K. J., Edwards, D., James, C. L., Thomas, A. M., and Ougham, H. J. 2007. Modification of nitrogen remobilization, grain fill and leaf senescence in maize (Zea mays) by transposon insertional mutagenesis in a protease gene. New Phytol. 173:481-494.

Ellis, J. G., Dodds, P. N., and Lawrence, G. J. 2007. Flax rust resistance gene specificity is based on direct resistance-avirulence protein interactions. Annu. Rev. Phytopathol. 45:289-306.

Hahnen, S., Joeris, T., Kreuzaler, F., and Peterhansel, C. 2003. Quantifica- tion of photosynthetic gene expression in maize $\mathrm{C}(3)$ and $\mathrm{C}(4)$ tissues by real-time PCR. Photosyn. Res. 75:183-192.

Hammerschmidt, R., and Nicholson, R. L. 1977. Resistance of maize to anthracnose-Changes in host phenols and pigments. Phytopathology 67:251-258.

He, P., Osaki, M., Takebe, M., Shinano, T., and Wasaki, J. 2005. Endogenous hormones and expression of senescence-related genes in different senescent types of maize. J. Exp. Bot. 56:1117-1128.

Horbach, R., Graf, A., Weihmann, F., Antelo, L., Mathea, S., Liermann, J. C., Opatz, T., Thines, E., Aguirre, J., and Deising, H. B. 2009. Sfp-type 4'-phosphopantetheinyl transferase is indispensable for fungal pathogenicity. Plant Cell 21:3379-3396.

Horst, R. J., Engelsdorf, T., Sonnewald, U., and Voll, L. M. 2008. Infection of maize leaves with Ustilago maydis prevents establishment of C-4 photosynthesis. J. Plant Physiol. 165:19-28.

Howlett, B. J. 2006. Secondary metabolite toxins and nutrition of plant pathogenic fungi. Curr. Opin. Plant Biol. 9:371-375.

Izui, K., Matsumura, H., Furumoto, T., and Kai, Y. 2004. Phosphoenolpyruvate carboxylase: A new era of structural biology. Annu. Rev. Plant Biol. 55:69-84.

Jobic, C., Boisson, A. M., Gout, E., Rascle, C., Fevre, M., Cotton, P., and Bligny, R. 2007. Metabolic processes and carbon nutrient exchanges between host and pathogen sustain the disease development during sunflower infection by Sclerotinia sclerotiorum. Planta 226:251-265.

Kim, J. Y., Mahe, A., Guy, S., Brangeon, J., Roche, O., Chourey, P. S., and Prioul, J. L. 2000. Characterization of two members of the maize gene family, Incw3 and Incw4, encoding cell-wall invertases. Gene 245:89102.

Krijger, J.-J., Horbach, R., Behr, M., Schweizer, P., Deising, H. B., and Wirsel, S. G. R. 2008. The yeast signal sequence trap identifies secreted proteins of the hemibiotrophic corn pathogen Colletotrichum graminicola. Mol. Plant-Microbe Interact. 21:1325-1336.

Leonard, K. J., and Thompson, D. L. 1976. Effects of temperature and host maturity on lesion development of Colletotrichum graminicola on corn. Phytopathology 66:635-639.

Liu, W. H., and Saint, D. A. 2002. Validation of a quantitative method for real time PCR kinetics. Biochem. Biophys. Res. Commun. 294:347353.

Maor, R., Puyesky, M., Horwitz, B. A., and Sharon, A. 1998. Use of green fluorescent protein (GFP) for studying development and fungal-plant interaction in Cochliobolus heterostrophus. Mycol. Res. 102:491-496.

McLaughlin, J. E., and Boyer, J. S. 2004. Sugar-responsive gene expression, invertase activity, and senescence in aborting maize ovaries at low water potentials. Ann. Bot. 94:675-689.

Mims, C. W., and Vaillancourt, L. J. 2002. Ultrastructural characterization of infection and colonization of maize leaves by Colletotrichum graminicola, and by a $C$. graminicola pathogenicity mutant. Phytopathology 92:803-812.

Nicholson, R. L., and Hammerschmidt, R. 1992. Phenolic compounds and their role in disease resistance. Annu. Rev. Phytopathol. 30:369-389.

Nicholson, R. L., Hipskind, J., and Hanau, R. M. 1989. Protection against phenol toxicity by the spore mucilage of Colletotrichum graminicola, an aid to secondary spread. Physiol. Mol. Plant Pathol. 35:243-252.

Ougham, H., Hörtensteiner, S., Armstead, I., Donnison, I., King, I., Thomas, H., and Mur, L. 2008. The control of chlorophyll catabolism and the status of yellowing as a biomarker of leaf senescence. Plant Biol. 10:414.

Oxborough, K. 2004. Imaging of chlorophyll a fluorescence: Theoretical and practical aspects of an emerging technique for the monitoring of photosynthetic performance. J. Exp. Bot. 55:1195-1205.

Patel, M., and Berry, J. O. 2008. Rubisco gene expression in C4 plants. J. Exp. Bot. 59:1625-1634.

Roitsch, T., Balibrea Lara, M. E., Hofmann, M., Proels, R., and Sinha, A. K. 2003. Extracellular invertase: Key metabolic enzyme and PR protein. J. Exp. Bot. 54:513-524.

Ruiz, E., and Ruffner, H. P. 2002. Immunodetection of Botrytis-specific invertase in infected grapes. J. Phytopathol. 150:76-85.

Scholes, J. D., Lee, P. J., Horton, P., and Lewis, D. H. 1994. Invertase Understanding changes in the photosynthetic and carbohydrate-metabolism of barley leaves infected with powdery mildew. New Phytol. 126:213-222.

Schreiber, U. 1994. New emitter-detector-cuvette assembly for measuring modulated chlorophyll fluorescence of highly diluted suspensions in conjunction with the standard PAM fluorometer. Z. Naturforsch. 49:646-656.

Smart, C. M., Hosken, S. E., Thomas, H., Greaves, J. A., Blair, B. G., and Schuch, W. 1995. The timing of maize leaf senescence and characterization of senescence-related cDNAs. Physiol. Plant. 93:673-682.

Spurr, A. R. 1969. A low-viscosity epoxy resin embedding medium for electron microscopy. J. Ultrastruct. Res. 26:31-43. 
Sukno, S. A., Garcia, V. M., Shaw, B. D., and Thon, M. R. 2008. Root infection and systemic colonization of maize by Colletotrichum graminicola. Appl. Environ. Microbiol. 74:823-832.

Swarbrick, P. J., Schulze-Lefert, P., and Scholes, J. D. 2006. Metabolic consequences of susceptibility and resistance (race-specific and broadspectrum) in barley leaves challenged with powdery mildew. Plant Cell Environ. 29:1061-1076.

Tang, W., Coughlan, S., Crane, E., Beatty, M., and Duvick, J. 2006. The application of laser microdissection to in planta gene expression profiling of the maize anthracnose stalk rot fungus Colletotrichum graminicola. Mol. Plant-Microbe Interact. 19:1240-1250.

Vandesompele, J., De Preter, K., Pattyn, F., Poppe, B., Van Roy, N., De Paepe, A., and Speleman, F. 2002. Accurate normalization of realtime quantitative RT-PCR data by geometric averaging of multiple internal control genes. Genome Biol. 3:0034.0031-0034.0011. Published online.

Venard, C., and Vaillancourt, L. 2007a. Colonization of fiber cells by Colletotrichum graminicola in wounded maize stalks. Phytopathology 97:438-447.

Venard, C., and Vaillancourt, L. 2007b. Penetration and colonization of un- wounded maize tissues by the maize anthracnose pathogen Colletotrichum graminicola and the related nonpathogen C. sublineolum. Mycologia 99:368-377.

Voegele, R. T., Struck, C., Hahn, M., and Mendgen, K. 2001. The role of haustoria in sugar supply during infection of broad bean by the rust fungus Uromyces fabae. Proc. Natl. Acad. Sci. U.S.A. 98:8133-8138.

Voegele, R. T., Wirsel, S., Möll, U., Lechner, M., and Mendgen, K. 2006. Cloning and characterization of a novel invertase from the obligate biotroph Uromyces fabae and analysis of expression patterns of host and pathogen invertases in the course of infection. Mol. Plant-Microbe Interact. 19:625-634

Voegele, R. T., Hahn, M., and Mendgen, K. 2009. The Uredinales: Cytology, biochemistry, and molecular biology. Pages 69-98 in: Plant Relationships. H. B. Deising, ed. Springer Verlag, Heidelberg.

Walters, D. R., McRoberts, N., and Fitt, B. D. L. 2008. Are green islands red herrings? Significance of green islands in plant interactions with pathogens and pests. Biol. Rev. Camb. Philos. Soc. 83:79-102.

Wingler, A., and Roitsch, T. 2008. Metabolic regulation of leaf senescence: Interactions of sugar signalling with biotic and abiotic stress responses. Plant Biol. 10:50-62. 